\title{
Reflections on the history of aquatic science in South Africa with particular reference to the period after 1994
}

\author{
Dirk J Roux ${ }^{1,2 *}$, Charles M Breen ${ }^{3}$ and Jane Carruthers ${ }^{4,5}$ \\ 'Scientific Services, South African National Parks, George, South Africa \\ ${ }^{2}$ Sustainability Research Unit, Nelson Mandela Metropolitan University, George, South Africa \\ ${ }^{3}$ School of Agriculture, Earth and Environmental Sciences, University of KwaZulu-Natal, Pietermaritzburg, South Africa \\ ${ }^{4}$ Department of History, University of South Africa, Pretoria \\ ${ }^{5}$ Centre for Invasion Biology, Stellenbosch University, Stellenbosch, South Africa
}

\begin{abstract}
In this article we reflect on how freshwater research has evolved in South Africa from its beginnings in the early $20^{\text {th }}$ century and how it has altered over time to align with the post-1994 socio-political environment. We situate aquatic science within a research question to explore why aquatic science has developed in the manner it has done, providing some of the broader environment of political change, access to funding, the relevance of particular research themes at different times, and the research agenda of some prominent individual scientists. We do not, therefore, intend merely to itemise what has been achieved over the years. Our intention is to develop an historical context that may help frame research in ways that bridge the cultural divides that persist between the humanities and the sciences. Moreover, although water is crucial to life and livelihoods in a country of scarce water resources, the fields of aquatic study are not generally familiar to the South African public and do not have the high profile they merit. In order to chart important current developments in freshwater research, this article highlights significant aspects of this scientific arena during the earlier part of the $20^{\text {th }}$ century that are pertinent to explaining how and why the current situation, by way of research fields, policy and legislation came into being. The history has been necessitated by, and driven by, regional socio-economic and geopolitical factors as well as developments in the relevant scientific disciplines. After examining how this state of affairs came to be, an overview of the present state of the field is provided.
\end{abstract}

Keywords: research milieu; key developments; drivers of change; institutional change; policy

\section{INTRODUCTION}

In South African research circles the call for multi-disciplinary research collaboration is frequently heard. More often than not, the envisaged 'multi-' of the disciplines are closely related ones. For example, a zoologist might work on an aquatic research project with a botanist. Indeed, in this paper we provide examples of the beneficial outcomes of this kind of partnership. Less common, however, is cooperation between what CP Snow famously referred to as 'the two cultures' - the humanities on the one hand and the sciences on the other (Snow, 1959). This division still exists. Historical analysis of science will be found in historical journals, scientific research in science journals. Each has avid readers, but straddling the two generally tends to offend either one constituency or the other as it seeks the reassuring markers of its modus operandi. Scholarly or academic history, viz. the discipline of history, is not a mere compilation of facts and dates, a miscellaneous collection of anecdotes or reminiscences, although this sometimes - at least to historians - appears to be the way that scientists regard the discipline, and even how the word 'history' is often utilised in scientific work. By contrast, scientists are impatient with levels of historical context and lengthy analytical narrative and do not always require the depth of understanding that history provides in order to pursue their craft or add value to it. Nonetheless, the urgency of many issues of our time - the Age of the

To whom all correspondence should be addressed. Im +27 44871 0109; e-mail: dirk.roux@sanparks.org Received 1 July 2013; accepted in revised form 5 March 2014.
Anthropocene, as termed by Nobel prize-winning chemist Paul Crutzen (Crutzen and Stoermer, 2000) - demands that all research arenas come to terms with what is possibly the greatest paradigm shift ever to have occurred - our realisation that humanity is a dominant force shaping the planet. Viewed from this perspective, the need to integrate science and humanity in matters such as global change foregrounds the importance of the humanities and demands that real multi-disciplinary work be conducted. This paper is a modest attempt to bridge Snow's divide. In it, we wish to indicate, but also to explain and provide understanding of, the manner in which changes in the political and technological arenas, institutional, funding and legislative arrangements as well as research agendas pursued by people with individual talents and interests, has impacted upon aquatic scientific research in South Africa in past decades and that resonate into the future.

Over the past 100 years South Africa has experienced a number of political changes that each required a new relationship between society and scientific research. The tectonic shift in South African politics after 1994 brought about a re-evaluation of both the political idea of the nation and its future socioeconomic priorities. However, no polity can act entirely independently and changes in South African freshwater research and policy have been impacted upon by international developments relating to sustainability, ecosystem services, complexity theory, multi-, inter- and trans-disciplinarity and an overarching research agenda around adaptive resource management. While internal factors are primarily driven by a national agenda, many external factors are not peculiar to South Africa. The year 1994 was not, however, the only political shift in South 
Africa that necessitated a new relationship between politics, society and science: other benchmark dates include 1910 when the Union of South Africa was established, and 1948 when the coming to power of the National Party led to a Republican constitution in 1961. These too made their mark on aquatic science and are briefly discussed below.

Although the importance of water is fundamental to human beings, as far as South African science is concerned, professional interest in freshwater studies was slow to develop. The manner in which this occurred provides longer-term context to explaining how that professional interest was shaped as well as the reach of its impact. In the early years of colonial settlement and into the early $20^{\text {th }}$ century, scholarly attention was devoted to astronomy, zoology, botany and veterinary sciences. In his autobiographical memoir, E Barton Worthington, freshwater ecologist and Director of the International Biological Programme (IBP) from 1964 to 1972, summarised freshwater biology in Europe by referring to its practical importance for recreational and professional fishermen, for pollution studies, for water engineering and studies on water-related diseases. Names such as FA Forel, who studied the limnology of Lake Geneva in the 1870s, or Otto Zacharias, who established his limnological research station in Plön in 1890, or even pioneers Edward A Birge and Chancey Juday of the University of Wisconsin, who worked on Lake Mendota in the early 1900s, attest to the long tradition of limnological research in Europe and the United States. Great Britain lagged behind in freshwater studies until around the time of the First World War, because before then its aquatic biologists 'were drawn to the seas rather than to inland waters' (Worthington, 1983). This comment may also apply to South African aquatic research because the first Government Biologist of the Cape Colony appointed in 1896, head of the Department of Zoology at the South African College from 1905 and its successor the University of Cape Town until 1926, was a marine biologist, the Edinburgh- and Germany-trained John DF Gilchrist. There is no evidence that any South African researcher belonged to the Freshwater Biological Association of the British Empire, of which the Union was, in 1929 when the Association was founded, firmly part. That South African limnology might have spawned the entire field of systems ecology was a potential consequence that could have arisen from the presence, at the University of the Witwatersrand, of G Evelyn Hutchinson in the mid-1920s. However, that opportunity was lost with his appointment at Yale University and his proposed work on the ecology of southern African freshwater bodies was never published (Carruthers, 2011).

It is probable that societies that rely on freshwater fish as a food supply and landscapes characterised by post-glacial lakes are more obvious sites for limnological studies (a word that applies to freshwater lakes although often employed more widely for freshwater sciences) than South Africa, with its more arid climate and its wide diversity of smaller water bodies. Indeed, it is that very diversity that makes the history of South African aquatic research extremely complex.

Owing to the immense variety it is not possible to survey the entire range of aquatic sciences in this paper. For example, hydrology, geomorphology or groundwater studies have not been included although these disciplines have been important in defining aquatic science in the country. Additionally, as a 'public good', water science is inherently political and the state's agenda impacts on the scientific one.

After an overview that identifies some of the important developments in freshwater research, this article explains, with reference to the period around 1994 and more recently, how these factors altered and shaped the framing of freshwater research in South Africa and, in addition, that may impact on the future. This article is based on a report entitled The Freshwater Science Landscape in South Africa, 1900-2010: Overview of Research Topics, Key Individuals, Institutional Change and Operating Culture (Ashton et al., 2012), published by the Water Research Commission. In the interest of length, the present article has a select list of references and readers are referred to the full list in Ashton et al. (2012).

\section{0-1948}

\section{Union legislation}

The Union of South Africa was formed in 1910 with the amalgamation of the four British colonies. In terms of freshwater science, the political mission of modernising the now-united and independent country economically was based on agricultural 'progress' within a worldview of increasing desiccation. In this regard, the formation of a Sub-Department of Irrigation, in a national Department of Lands in 1912, together with the Irrigation and Conservation of Waters Act (No. 8 of 1912) were important. The construction of a series of large dams (which had the added benefit of white labour during the period of upliftment of 'poor whites' as part of the social engineering programme) was done as a socio-economic benefit (Van Vuuren, 2012). The socio-political agenda with a focus on agricultural productivity was pivotal in developing the legislative framework and early research agenda of freshwater studies. Dam-building also had later impacts on aquatic science as eutrophication over the longer-term led to exponential growth of aquatic biota that required research.

The 1912 Act was not a scientific template, but provided a regulatory and dispute-resolution mechanism that imposed country-wide order on the diversity of water rights in what had been four separate colonies since 1902, viz. the Cape, the Orange Free State, Natal and the Transvaal. Government-led freshwater science was not a legal mandate (unlike marine science) and such research was directed by the interests of farmers and of recreational fishermen (through piscatorial and acclimatization societies such as the Transvaal Trout Acclimatization Society and the Western Districts Acclimatization Society) who advocated the introduction of, and study of, imported fish species, as well as by individuals in South Africa's museums or establishments of higher education. The South African Museum in Cape Town, the Transvaal Museum in Pretoria, and the Natal Museum in Pietermaritzburg contained collections that were used sporadically. In 1910 there was only one university, the University of the Cape of Good Hope (reconstituted as the University of South Africa in 1916) examining for the University of London, and it eventually spawned other universities, many of which had previously been 'university colleges' attached to it. Some of these institutions attracted people keen on freshwater study but their efforts were sporadic and were often indistinguishable from general zoology or botany.

\section{Biological and aquatic studies}

In the early $20^{\text {th }}$ century, the adjective 'biology' was applied to many studies of the natural world and, in this period when generalisation not specialisation was the norm, many professors and lecturers switched between disciplines with ease. In terms of freshwater research specifically, one might mention the 
foundational work of G Evelyn Hutchinson, Cambridge-trained and briefly in the Department of Zoology at the University of the Witwatersrand in the mid-1920s. He studied the limnology and biota of pans and other inland water bodies, often with the collaboration of his wife, Grace Pickford, and his colleague, Johanna Schuurman (Hutchinson et al., 1929; Hutchinson et al. 1932). Hutchinson went on to Yale University where he became one of the founders of systems ecology based on his limnological investigations with brilliant students such as Raymond Lindeman. Also significant was government marine biologist John DF Gilchrist mentioned above. He produced the first catalogue of South African freshwater fishes (Gilchrist and Thompson, 1913), while South African museum zoologist KH (Keppel) Barnard published on fish taxonomy (Barnard, 1947).

In the first decades of the $20^{\text {th }}$ century there was no tradition of citations or even academic journals as currently known. However, limnology was a well organised study and an International Association for Theoretical and Applied Limnology was founded in 1922, but no South African worker appears to have been a member during this period. The most prestigious freshwater science journal of the time was the Archiv fur Hydrobiologie (founded in 1906 and currently named Fundamental and Applied Limnology), which has always accepted articles in English, but Hutchinson, Pickford and Schuurman appear to have been the only South African-based scientists to publish in its pages during this period.

\section{8-1994}

\section{Science in South Africa after World War II}

The Second World War had an unprecedented impact on science. In many countries an atomic age dawned with the belief that 'big science' and technology were all powerful and could provide solutions that would ensure 'progress'. In addition, South Africa was confronted with a new political dispensation and socio-economic priorities when the National Party came to power in 1948 . This set the country on the trajectory of apartheid, but also reconfigured the civil service and introduced Afrikaner employment affirmative action. The result was increasing international isolation and eventually total alienation (as a Republic in 1961) from the British Commonwealth and the severing of international scientific ties. It also brought top-down autocratic 'big government' and silenced much of the voice of civil society. This was a time of global prosperity and, like other states, the South African Government invested heavily in science and technology. Although many projects related to national security and defence, sufficient money was available to spend also on the environment and natural sciences, much of which related to the water sector. There is no doubt that the rise of the international environmental movement of the 1960s and 1970s, together with the growing influence of international environmental governance (e.g. the Ramsar Convention of 1971, the United Nations Conference on the Human Environment, Stockholm, 1972), played their part in encouraging ecological and environmental state-sponsored research. Moreover, the era of the sole worker was waning and research projects became increasingly collaborative, bringing about the need to focus on the management of these larger and more complex projects and not only on the research field. Significantly, the acceptance of Arthur Tansley's (and others) term 'ecosystem' broadened the multi- and inter-disciplinary research agenda considerably by emphasising biophysical connectedness and change in natural systems.

\section{Role of the Council for Scientific and Industrial Research}

As many other countries did at this time, South Africa established a quasi-independent para-statal, the Council for Scientific and Industrial Research (CSIR), in 1945. An early arm of the CSIR was the 1958 National Institute for Water Research (NIWR) that undertook a number of surveys of the fauna, flora and physico-chemistry of many South African rivers, one of which was a publication on the Great Berg River by Arthur Harrison and Jack Elsworth. This was the first research on a South African river and one of the earliest significant publications on the ecology of rivers anywhere in the world. The twopart publication on the hydrobiology of the Great Berg River covered river zonation, flow, water quality and floristic features but the larger focus was on invertebrate fauna (Harrison, 1958; Harrison and Elsworth, 1958).

For some time before its political and scientific isolation, South Africa remained within the International Council for Scientific Unions (ICSU) and its Scientific Committee for Problems of the Environment (SCOPE) founded in 1970. Under SCOPE the country established the National Programme of Environmental Sciences (NPES) in 1972 and also participated in the International Biological Programme that ran between 1964 and 1974 that introduced South African scientists to collaborative programmatic approaches to research addressing the nature and behaviour of aquatic systems. In 1975 the NPES was transformed into the Cooperative Scientific Programmes (CSP) within the CSIR with direct beneficial consequences for the ecological sciences. These programmes, under the auspices of the National Programme for Ecosystem Research (NPER) (1976-1985) produced almost 100 extremely well researched and important reports, supported 208 individual projects within 22 cooperative ventures and received R9.2 million in funding (Huntley, 1987). Not only was the content of these reports scientifically noteworthy, but they heralded a move towards collaborative research that made consideration of large ecological issues feasible (Noble and Hemens, 1978; Heeg and Breen, 1982; Hart and Allanson, 1984; National Institute for Water Research, 1985; Ferrar, 1989).

\section{New legislation and the establishment of the National Institute of Water Research and the Water Research Commission}

The CSIR was instrumental in shaping South African science during this period because of its leading role in the CSP and in distributing research grants. Indeed, some seasoned researchers look back on it as a kind of golden age, with scientific imagination given virtually free rein. Of particular significance for freshwater studies was the establishment of the NIWR with a mandate to investigate pollution and ensure fresh water for industry. Government involvement in freshwater research included a new Water Act (No. 54 of 1956) that codified effluent and other standards and that resulted in the establishment of a separate Department of Water Affairs. Moreover, the high national importance of water was further recognised by Government through the launch of the Commission of Enquiry into Water Matters in 1966. The final report of this Commission was published about a decade later in 1970, which led directly to the establishment in 1971 of the Water Research Commission (WRC). The WRC became the key mechanism for funding water research in South Africa. The WRC was instituted outside of the government Department of Water Affairs and it is financed by a levy on water users. It is 
thus independent and relatively well funded, even today. Not surprisingly, the research initiatives that included estuaries, rivers, hydrology and engineering, etc., were focused on the use of water for national economic development by way of use or conservation rather than on fundamental research. One particular research problem was, in fact, occasioned by the ongoing policy of dam-building, i.e. that of eutrophication.

Until about 1980, access to research funding was filtered to universities largely through the CSIR (Kingwill, 1990). Research units were awarded to outstanding or high-achieving researchers. Almost every South African university received this form of government support. Nonetheless, the most important nodes of freshwater research remained Rhodes University, particularly after the appointment of Brian Allanson from the NIWR to the Chair of Zoology and Entomology in 1963 (he established the Institute of Freshwater Studies the following year and became its Director), and the University of Cape Town where John Day was Professor of Zoology from 1948.

Adding to the dynamism of this post-war period was the foundation of the South African Limnological Society in 1963, later renamed the Southern African Society of Aquatic Scientists (SASAqS). This Society has convened regular conferences and provided a forum for wide-ranging discussions that usually included international contributions. Like many others of its kind, however, SASAqS has alternated periods of vibrancy with decline, often related to the fervour of committee members and organisers, a comment that applies also to its journal.

Recognition of the need to protect at least some freshwater ecosystems against human-induced degradation gave rise to the development of the first nation-wide freshwater conservation plan for South Africa in the 1970s. Graham Noble, an aquatic scientist himself and one of the leaders of the CSIR programmes, evaluated the conservation status of some 40 aquatic biotopes that were classified according to a mixture of biological and physical attributes (Noble, 1974). This study produced a protected-area gap analysis, an approach that would only be formalised in terrestrial conservation planning some 20 years later. After a decade of work, a different approach was taken to identify 144 South African river sites of outstanding conservation importance in order to have a baseline for conservation action (O'Keeffe, 1986). In an attempt to be more quantitative and consistent, this project was followed by the development of an expert-driven River Conservation System to assess the relative importance of different rivers and to communicate the results to decision-makers (O'Keeffe, 1986; O'Keeffe et al., 1987a; O'Keeffe et al., 1987b; O'Keeffe, 1989). This system offered flexibility over traditional scoring approaches in that it provided rules that could be applied to alter the weightings according to a variety of settings (e.g. regional differences in biota, differences related to river size).

\section{Changes in funding structures: the $1980 \mathrm{~s}$}

The above-mentioned largesse of the CSIR could not last forever nor could it withstand a recession that began with a rising oil price and high inflation, increasing internal unrest and external war for South Africa, and the burgeoning costs of 'national and self-governing states' such as the Ciskei, Transkei and Bophuthatswana. The first indication of a contraction in spending came with the establishment of the Foundation for Research Development (FRD) within the CSIR that abandoned the long-term programmatic approach to environmental research. While many university research entities that had been supported continued to exist, they had to find alternative sources of finance. Moreover, the entire philosophy of the CSIR came under scrutiny and the policy of generous open-ended support was replaced in 1988 by a neo-liberal partnership between Government and the private sector in which research was overtly goal- and business-directed and conducted on a consultancy and contract basis, thus providing external funding to the CSIR.

This change in the funding and business models for research, which was a global phenomenon (Ziman, 1996) but perhaps compounded in South Africa due to country-specific drivers, was bound to have repercussions. That a negative mood had emerged in the freshwater research sector became evident in 1989 with a report commissioned by the FRD to evaluate the Inland Water Ecosystems Programme (IWEP). Among the first CSP research programmes, the IWEP consisted of seven groups of research projects on lakes, reservoirs, rivers, wetlands and pans. Professor WD Williams of the University of Adelaide was appointed, because of his high international profile and long experience with water management in an arid environment, to assess these projects. While Williams (1989) complimented the IWEP on its wide coverage of the freshwater landscape and on initiating research that would lead to understanding the structure and functioning of South Africa's inland aquatic resources, he also brought strong criticism. In particular he noted that much of the research remained unpublished and that research findings had not been applied. This seemed to indicate that the earlier work of the CSP had not had the necessary effect, despite both research energy and ample funding at the time. Williams concluded that, as the 1990s dawned, South African limnology was in disarray, poorly funded in the new dispensation, failed to address certain important environmental problems and lacked direction. Many of its practitioners were dispirited, numbers were declining and few young people were attracted to water science as a career.

In 1986 the Department of Water Affairs and Forestry had published Management of the Water Resources of the Republic of South Africa, an important report that called for research that would determine the water needs of the natural environment. A group convened by the CSIR responded with The Ecological Flow Requirements for South African Rivers (Ferrar, 1989), which captured the foundational concepts upon which all of the flow-assessment methods for rivers in South Africa were subsequently based. There were globally important results because the holistic approach adopted was predicated on recognising that all parts of the ecosystem needed to be considered - including land - and not merely water or selected species in isolation. Through the development and testing of various methods and approaches - together with growing access to computer systems - a structured multidisciplinary approach was introduced to assessing flows for ecosystem maintenance. Disciplines that collaborate in these assessments include hydrology, hydraulics, geomorphology, water chemistry, zoology (fish, invertebrates), botany (aquatic, marginal and riparian vegetation), sociology and socio-economics (King and Pienaar, 2011).

The period between the end of the Second World War and democratic elections in 1994 with its change of Government, had witnessed a new aquatic research framework developing within South Africa, with the role of the CSIR being critical. However, it was also a period in which South Africa became more politically and scientifically isolated internationally, and one towards the end of which the commercialisation of science (Gibbons et al., 1994; Slaughter and Rhoades, 1996) had become a reality not only within the country but also globally. 


\section{AND THEREAFTER}

\section{Water legislation and management under new socio- economic and political priorities}

In 1994 the new government inherited a country that had lived beyond its financial means for many years, a large African population demanding services which it had been denied for decades, and the legacy of a very large (and generally inefficient) civil service of the previous Bantustans that had to be incorporated into the new provincial structures. The changes that came about in this period alienated some senior officials and technocrats, as had happened previously in 1910 and in 1948. But water - its supply and quality - was an urgent state priority and the Department of Water Affairs and Forestry, headed by Minister Kader Asmal, was tasked with providing an Overview of Water Resources Availability and Utilization in South Africa (Basson et al., 1997). This report appeared in 1997 and in the same year two other important documents that changed the institutional and legal framework of freshwater research were also published. These were the White Paper on a National Water Policy tabled in May 1997 and a new Act, the Water Services Act (No. 108 of 1997). The National Water Act (No. 36 of 1998) was another consequence of the new political and legal regime, intended to ensure sustainability and to redress past imbalances in water provision. The WRC took over many of the programmes previously funded by the CSIR or FRD. Thus a changed environment for aquatic research came into play and one driven by the concerns and interests of broader society: in essence aquatic scientists were directly engaged in providing a service to society. There were also suggestions that some of the important outcomes of the NPER programmes would have socio-economic benefits if theoretical underpinning was enhanced, among them the long-term study of the Pongolo River Floodplain (Huntley, 1987). Scientists were given a voice and SASAqS members were appointed to the Water Law Review Panel and continued to be influential in the WRC, which now had a section focussed specifically on funding freshwater ecosystem research. The concept of an 'ecological Reserve' in water management, for example, was the idea of SASAqS member Professor Caroline (Tally) Palmer, who is currently the Director of the Unilever Centre for Environmental Water Quality within the Institute for Water Research at Rhodes University.

Thus the SASAqS, as the professional scientific organisation, was given a stronger influence in setting the research agenda and shaping water policy. The link between science and society that became closer after 1994 encouraged an approach that was inter- and even trans-disciplinary, including not only the natural sciences, but also the social sciences for the first time. No longer, in the words of Kevin Rogers, were 'expert scientists saving ignorant society'; on the contrary, society was brought within the research partnership, not thrust outside of it. At times this may have been a difficult brief, because - again quoting Rogers - 'The narrow disciplinary training of scientists and other professionals involved in river research does not equip them well for interdisciplinary work' (Rogers, 2006). Yet, some early interdisciplinary work (e.g. Heeg and Breen, 1982) provided a good basis for integrative aquatic science.

\section{Emphasis on ecosystem services and alignment with international priorities}

With the passage of the 1998 National Water Act it became a legal requirement to reserve water to maintain the country's aquatic ecosystems so that they could provide the ecosystem services upon which society depended. This major milestone was followed by a second when the Directorate of Resource Directed Measures (RDM) was established within the Department of Water Affairs and Forestry in 2002, to ensure adequate protection of ecosystems. The RDM has three main elements. First, there is a catchment-based classification system for water resources, which guides the setting of one of three management classes for each part of the catchment's water resources. Second, the concept of an ecological Reserve, viz. the quantity and quality of water linked to each of those management classes, was developed, and third, resource quality objectives (RQOs) came into being. These are quantitative and qualitative descriptions of the hydrological, chemical, physicochemical, geomorphological and biological attributes that can be monitored for compliance of the management classes.

After 1994 South Africa re-engaged with the international community and became a signatory to a number of important global institutions that impacted on water research, in particular the Convention on Biological Diversity, the Man and the Biosphere Programme, and the World Heritage Convention. In terms of the last-mentioned, South Africa's first listed natural World Heritage Site (WHS) was water-research related - the iSimangaliso Wetland Park in KwaZulu-Natal - while the wetlands and water resources of the Drakensberg (already Ramsar Site No. 886) were important in the declaration of the uKhahlamba-Drakensberg WHS, listed as a 'mixed' WHS, in 2000. International respectability resulted also in Port Elizabeth's hosting of the International Environmental Water Allocation conference in 2009, while Cape Town welcomed Africa's first International Limnological Conference in 2010. Such august gatherings hold promise for synergy and new directions.

International normalisation and the lifting of the academic boycott brought South African freshwater scientists in closer contact with their global peers and opened opportunities for international collaboration as well as access to international funding sources. This affected both the research agenda and research institutions. The construction of large dams had become extremely controversial, but, as far as scientists were concerned, their social and environmental consequences in terms of water quality, eutrophication and invasive vegetation raised new research questions relating to appropriate landuse and, more broadly, to sustainability. The contribution of impoundments to the national economy had declined with widespread changes within the agricultural sector, while issues around water quality and rivers gained in scientific importance, particularly with the rise of concepts such as ecosystem services. Collecting and interpreting data had been revolutionised by GIS and computer modelling.

\section{River systems and attenuation dams: Kruger National Park as a case study}

The main thrust of innovative water research in South Africa in recent years has been around investigating river systems because of compromised water quality through attenuation dams, pollution, and extraction and heavy usage by a growing rural and urban population. When the rivers traversing the Kruger National Park appeared to be at risk from upstream activities in the late 1980s, river research gained ground. In 1987 the Department of Water Affairs and Forestry became involved, and the Kruger National Park Rivers Research Programme (KNPRRP) was initiated the following year as a joint venture between the Department, the WRC and the FRD. 
This research came to fit well with the new strategic adaptive management regime in the Kruger National Park, and also with emerging ideas around the complexities of savanna ecosystems and the understanding of river catchments in this context. Considerable progress was made in understanding the structure and functioning of river systems and the influence that the KNPRRP has had in the development and adoption of adaptive management and complexity theory is widely acknowledged.

A large number of agencies and universities participated in the KNPRRP and many prominent scientists contributed in various ways, furthering their own knowledge and capacity by collaborating with others. The first phase, until 1992, was a loose assemblage of useful projects, but the second and third phases were more structured so as to align the studies and produce a better organised scientific foundation for adaptive management of river flow. The resultant decision support system was sufficiently generic to find application in the wider field of natural resource management. The KNPRRP foregrounded the importance of considering multiple scales together with the heterogeneity and dynamism that had become the hallmarks of early $21^{\text {st }}$ century ecological thinking (Rogers and Bestbier, 1997; Rogers and Biggs, 1999; O’Keeffe and Rogers, 2003; Rogers, 2006). In the early 2000 s the programme formally ended, but river research continued as the Shared Rivers Initiative (SRI). The SRI has not generated the research results or the excitement of the earlier KNPRRP collaboration, but it continues into the present. It currently focuses on understanding why environmental flows are not met, on action research, social learning and governance. This can be interpreted as moving towards a holistic socio-ecological systems view that integrates policy with research.

In the early 1990s, the Department of Water Affairs and Forestry commissioned the design of a new national monitoring programme, which would become known as the River Health Programme (RHP). The RHP was designed to assess the ecological condition of rivers by using biological indicators such as fish communities, invertebrate fauna and riparian vegetation. This monitoring approach provided water quality managers, who had previously relied almost solely on information gained from the monitoring of chemical and physical water quality variables, with a new type of information and new insights into the ecological state of rivers in South Africa. Scientists from the University of Cape Town developed a spatial classification of rivers, and protocols for the selection of monitoring and reference sites, while scientists from Rhodes University were conspicuous in reviewing and recommending ecological indicators for use in the programme. The RHP was implemented across several provinces and a number of 'stateof-river' reports were produced (Strydom et al., 2006).

\section{The National Spatial Biodiversity Assessment}

In the 2000s systematic planning principles drove the first comprehensive National Spatial Biodiversity Assessment (NSBA) (Driver et al., 2004). It dealt with terrestrial, river, estuary and marine ecosystems but not wetlands, which were too poorly known for an adequate assessment to be made. The NSBA highlighted the overall poor state of South Africa's river systems, heightening awareness of the urgency for strategic conservation action to protect freshwater biodiversity. The development of policy objectives for facilitating cross-sector collaboration and coordination in the management of freshwater biodiversity, and an overview of prospects and challenges in freshwater conservation planning, developed this new branch of science further (Roux et al., 2008; Nel et al., 2009). These developments culminated into identifying freshwater ecosystem priority areas (FEPAs) comprising $22 \%$ of South Africa's river length, $38 \%$ of wetland area and $41 \%$ of estuaries (Nel et al., 2011). The implementation-driven FEPAs are directly applicable to various management tools within the biodiversity and water policy sectors in South Africa, such as integrated catchment management, water resource classification, listing of threatened river ecosystems, and the process of bioregional planning. As such, freshwater conservation planning has the potential to contribute significantly to sustainable and integrated water resource management in South Africa.

Initially, water resource planners had not considered the potential adverse environmental impacts of IBTs that moved water across watersheds, from where it occurred to where it was needed, for industry, cities and agriculture, including transfrontier supplies from neighbours like Lesotho. By the time that environmental concerns were taken into account in the late 1990s, the effects of IBTs on receiving waters in many parts of the country were probably irreversible. Ecologists Bryan Davies and Jim Cambray were among those who emphasised the deleterious consequences of IBTs on biodiversity and ecosystem conservation. Proper deliberation on the potential environmental consequences of IBTs was thus required. Thanks to these efforts, any proposed IBT now requires an in-depth environmental impact assessment.

\section{Systematics and taxonomy}

The study of systematics has been rejuvenated in the last couple of decades by considerable advances in methods for examining genetic relationships between individuals, populations, species and higher taxa. This has been particularly rewarding in the south-western Cape, where many rivers have existed for tens of millions of years and freshwater taxa have thus been isolated from each other for as long. A number of biologists have shown that even when taxa that are morphologically indistinguishable (or nearly so), some may be genetically very distinctive. Despite genetics, older themes, such as taxonomic studies of plants and animals, have not entirely abated, and good field guides to the aquatic and wetland plants of southern Africa have been produced. From a systematic point of view the different taxa of freshwater invertebrates have been unevenly treated, and it is likely that many new forms await description. However, modern systematics is more than simple descriptions of species; today, genetic studies are crucial for understanding the relationships between taxa.

\section{Research and policy partnerships}

Indicative of the crucial role of water in South Africa, in May 2009 the Department of Water was separated from forestry within the renamed Ministry of Water and Environmental Affairs. As can be appreciated from this overview, the relationship between the aquatic research community and the Department of Water Affairs is close and productive - and even more so with the WRC - but scientists have frequently found themselves having to provide rather hasty policy and directional answers. Despite the challenges, this may, in fact, be the usual manner in which policy and science intersect. In addition, there has been a bifurcation of scientists in the water sector. On the one hand, the role of consultancies (often staffed with well-qualified freshwater scientists) has grown in response to the need for broad-ranging applied science demanded by 
government, mining and other industries, with reports and outputs in the grey literature. On the other hand, owing to funding structures in the tertiary education sector, scientists in universities have been obliged to become narrower and to chase peer-reviewed journal publications and National Research Foundation academic ratings.

\section{CONCLUSION}

'History does not offer lessons. But it does suggest possibilities - and apart from the specific possibilities that a rich and complex story of the past establishes - the telling at least establishes that alternatives have existed in the past, that choices have been made, that choices have consequences' (Cooper, 2000). While historical analysis cannot provide a future template, providing a long-term overview of freshwater science within its sociopolitical and funding context gives perspective that may enable researchers to understand the basis of their disciplinary cluster and might suggest future productive avenues. This conclusion thus summarises key points and notes some ways in which a fruitful research agenda can be strengthened and developed.

It is evident that, of all South Africa's natural resources, fresh water is a public good- whether rivers, impoundments, groundwater or wetlands. Because human welfare absolutely depends on it, it is inherently the most political and the most relevant to society, particularly in an emerging economy or a developmental state. South African researchers can make a major international contribution in this arena. It is therefore necessary that professional freshwater scientists become co-collaborators with government, policy-makers and all stakeholders, so that fundamental scientific questions are not obscured or ignored by the need for 'quick-fixes' that ad hoc solutions can supply. Indeed, perhaps it is necessary to redefine the principles of collaboration in order that appropriate scientific and societal outcomes are delivered. It would be productive were institutional, disciplinary and policy agendas to interface better than they do at present, and take into account the different expectations, values, culture, language and reward structures of the main participating groups, the funders, researchers and end users. Avenues for the co-production of knowledge should be sought (Roux et al., 2010). Building on the concept of 'postnormal' science (Funtowicz and Ravetz, 1993), Rogers (2008) stresses that purely technical solutions to socio-ecological problems are untenable. Humility, rather than arrogance is now required. Disputed facts, competing values, enormous complexity and previous decisions and histories all intervene in the process of research and decision-making. Of all the branches of science, aquatic science - a public good, integrally linked to human welfare, broadly biological but itself multi-disciplinary - is well placed to lead the way (Rogers, 2008).

Although funding is vital for fundamental research, the generous support of the CSIR did not lead either to appropriate publication of those findings, nor to their application, as was shown by Williams's 1989 evaluation. Strategic and careful use of money is therefore called for. What the CSIR programmes did achieve was to instigate long-term institutional arrangements for the water sector and encourage an energetic research agenda in partnership with Government. How best to employ stable institutions, such as the WRC, and revitalise and augment the research community are current challenges.

As has been shown, the line between fundamental and applied science in freshwater research is a very thin one - some would argue that it is seamless. The research efficacy of collaborative and co-operative multi-disciplinary research in many aspects of aquatic studies has been proven since the 1980s. Integrated, structured and co-ordinated research towards well-articulated goals must be carefully planned and well supported. However, national research and funding structures do not consistently reward group-based scientific investigation, particularly within the university arena. Consultants, however, are free from the need to develop professionally within the higher education structure, with the concomitant danger that the absence of peer review may result in inadequate science. This is not to disparage problem-solving or problem-focussed research - this is vitally important. It drives engagement and creates passion and energy. However, without integrating long and short-term research agendas crisis management can result, while adherence to a programmatic approach alone can become top-heavy and generate research that has little relevance in the real world.

Because freshwater studies are so diverse and multi-faceted, despite their societal importance they are not familiar to the general public and are difficult to portray as engaging and attractive employment. Opportunities can be found to embark upon a planned campaign describing the coherence of the research avenues and the opportunities there are to improve life and livelihoods in South Africa through a career in water research. A higher profile for aquatic studies would be beneficial for the nation as well as for the discipline.

As explained above, legislation and government policy are deeply interwoven and even implicated in aquatic research. Water is inextricably bound up with social and economic outcomes and developmental goals. Making water available for consumption by a growing and mobile population and ensuring the health of river systems, estuaries and wetlands is a Government priority - indeed a prime responsibility - particularly when ecosystem services are brought into the picture.

Interventions such as Working for Water and Working for Wetlands have high profiles, have captured the public imagination, and have impacted on employment and skills development. Rigorous research into the efficacy and direction of these programmes in terms of scientifically-proven desirable outcomes could be improved and would boost rewarding partnerships between the research and policy sectors.

There is no doubt that reflection on scientific endeavour is productive. Currently in South Africa access to research funding is competitive, capacity is not easy to build, and educational institutions are under pressure. How this situation came about, and how it might be improved and mitigated given the multitude of challenges facing the country, requires coordinated thinking from all elements of society. However, in the vital arena of freshwater studies, it is important that on-going relevant research is encouraged by the state, that such research is well planned, collaborative, relevant and significant, and that scientists are supported and valued by the wider society. Moreover, this overview has shown the value of intellectual creativity, but also how more recently it has had to make way for the need to solve problems more directly. It has exposed the central importance of the institutional and social dimensions of successful research endeavour in natural resource management, and ultimately suggests the need for revising the philosophy that underpins the support for, and practice of, aquatic science in South Africa.

\section{ACKNOWLEDGEMENTS}

The authors would like to thank all those who contributed to the WRC project (K8/852) and report (Ashton et al., 2012), upon which this article is based, as authors, informants, referees and 
readers. Additional assistance and ideas were provided by Brian Huntley and Tony Little. The comments of two anonymous reviewers assisted greatly in revising an earlier draft of this manuscript.

\section{REFERENCES}

ASHTON P, ROUX D, BREEN C, DAY J, MITCHELL S, SEAMAN M and SILBERBAUER MJ (2012) The freshwater science landscape in South Africa, 1900-2010: Overview of research topics, key individuals, institutional change and operating culture. WRC Report No. TT 530/12. Water Research Commission, Pretoria.

BARNARD KH (1947) A Pictorial Guide to South African Fishes: Marine and Freshwater. Maskew Miller, London.

BASSON MS, VAN NIEKERK PH and VAN ROOYEN JN (1997) Overview of Water Resources Availability and Utilization in South Africa. Department of Water Affairs and Forestry and BKS (Pty) Ltd., Pretoria.

CARRUTHERS J (2011) G Evelyn Hutchinson in South Africa, 1926 to 1928: 'An immense part in my intellectual development'. Trans. $R$. Soc. S. Afr. 66 (2) 87-104.

COOPER F (2000) Africa's Pasts and Africa’s Historians. Can. J. Afr. Stud. 34 (2) 312.

CRUTZEN PJ AND STOERMER EF (2000) The Anthropocene. IGBP Newsletter 41. Royal Swedish Academy of Sciences, Stockholm.

DRIVER A, MAZE K, LOMBARD AT, NEL J, ROUGET M, TURPIE JK, COWLING RM, DESMET P, GOODMAN P, HARRIS J and co-authors (2004) South African National Spatial Biodiversity Assessment 2004: Summary Report. South African National Biodiversity Institute, Pretoria.

FERRAR AA (1989) Ecological Flow Requirements of South African Rivers. Foundation for Research Development, CSIR, Pretoria.

FUNTOWICZ SO and RAVETZ JR (1993) Science for the post-normal age. Futures 25 739-755

GIBBONS M, LIMOGES C, NOWOTNY H, SCHWARTZMAN S, SCOTT P and TROW M (1994) The New Production of Knowledge: The Dynamics of Science and Research in Contemporary Societies. Sage, Beverly Hills.

GILCHRIST J and THOMPSON W (1913) The Freshwater Fishes of South Africa. Ann. S. Afr. Mus. 11 321-462.

HARRISON AD (1958) Hydrobiological studies on the Great Berg River, Western Cape Province. Part 2. Quantitative studies on sandy bottoms, notes on tributaries and further information on the fauna, arranged systematically. Trans. R. Soc. S. Afr. 35 (3) 227-276.

HARRISON AD and ELSWORTH JF (1958) Hydrobiological studies on the Great Berg River, Western Cape Province. Part 1. General description, chemical studies and main features of the flora and fauna. Trans. R. Soc. S. Afr. 35 (3) 125-226.

HART RC and ALLANSON BR (1984) Limnological Criteria for Management of Water Quality in the Southern Hemisphere. South African National Scientific Programmes Report No. 93. Foundation for Research Development, CSIR, Pretoria.

HEEG J and BREEN CM (1982) Man and the Pongolo Floodplain. South African National Scientific Programmes Report No. 56. CSIR, Pretoria.

HUNTLEY BJ (1987) Ten years of cooperative ecological research in South Africa. S. Afr. J. Sci. 83 (2) 72-79.

HUTCHINSON GE, PICKFORD GE and SCHUURMAN JFM (1929) The inland waters of South Africa. Nature 123 832-833.

HUTCHINSON GE, PICKFORD GE and SCHUURMAN JFM (1932) A contribution to the hydrobiology of pans and other inland waters of South Africa. Archiv fur Hydrobiol. 24 1-154.

KING JM and PIENAAR HH (2011) Sustainable Use of South Africa's Inland Waters: A Situation Assessment of Resource Directed Measures 12 Years After the 1998 National Water Act. WRC Report No. TT 491/11. Water Research Commission, Pretoria.

KINGWILL DG (1990) The CSIR: The First 40 Years. CSIR, Pretoria.

NATIONAL INSTITUTE FOR WATER RESEARCH (1985) The Limnology of Hartbeespoort Dam. South African National Scientific Programmes Report No. 110. Foundation for Research Development CSIR, Pretoria.
NEL JL, DRIVER A, STRYDOM W, MAHERRY A, PETERSEN C, HILL L, ROUX DJ, NIENABER S, VAN DEVENTER H, SWARTZ E and co-authors (2011) Atlas of Freshwater Ecosystem Priority Areas in South Africa: Maps to support sustainable development of water resources. WRC Report No. TT 500/11. Water Research Commission, Pretoria.

NEL JL, ROUX DJ, ABELL R, ASHTON PJ, COWLING RM, HIGGINS JV, THIEME M and VIERS JC (2009) Progress and challenges in freshwater conservation planning. Aquat. Conserv: Mar. Freshwater Ecosyst. 19 474-485.

NOBLE RG (1974) An evaluation of the conservation status of aquatic biotopes. Koedoe 17 71-83.

NOBLE RG and HEMENS J (1978) Water Ecosystems in South Africa - A Review of Research Needs. Council for Scientific and Industrial Research, Pretoria.

O'KEEFFE JH (1986) The Conservation of South African Rivers. South African National Scientific Programmes Report No. 131. Foundation for Research Development, CSIR, Pretoria.

O’KEEFFE JH (1989) Conserving rivers in southern Africa. Biol. Conserv. 49 255-274.

O'KEEFFE JH, ASHTON PJ, BRINK P, BRUWER CA, ENGELBRECHT J, HAMMAN K, KING JM, KLEYNHANS CJ, PORTER R, SKELTON P and co-authors (1987a) A National Classification System for Rivers. In: Proceedings of a Workshop on River Classification, held at Lydenburg, Transvaal. Foundation for Research Development, CSIR, Pretoria.

O'KEEFFE JH, DANILEWITZ DB and BRADSHAW JA (1987b) An 'expert system' approach to the assessment of the conservation status of rivers. Biol. Conserv. 40 69-84.

O'KEEFFE JH and ROGERS KH (2003) Heterogeneity and the management of lowveld rivers. In: Du Toit JT, Rogers KH and Biggs HC (eds.) The Kruger Park Experience - Ecology and Management of Savanna Heterogeneity. Island Press, Washington DC.

ROGERS KH (2006) The real river management challenge: Integrating scientists, stakeholders and service agencies. River Res. Appl. 22 269-280.

ROGERS KH (2008) Limnology and the post-normal imperative: An African perspective. Verh. Internat. Verein Limnol. 30 (2) 171-185.

ROGERS KH and BESTBIER R (1997) Development of a Protocol for the Definition of the Desired State of Riverine Systems in South Africa. Department of Environmental Affairs and Tourism, Pretoria.

ROGERS KH and BIGGS HC (1999) Integrating indicators, endpoints and value systems in strategic management of the Kruger National Park. Freshwater Biol. 41 439-451.

ROUX DJ, ASHTON PJ, NEL JL and MACKAY HM (2008) Improving cross-sector policy integration and cooperation in support of freshwater conservation. Conserv. Biol. 22 1382-1387.

ROUX DJ, STIRZAKER RJ, BREEN CM, LEFROY EC and CRESSWELL HM (2010) Framework for participative reflection on the accomplishment of transdisciplinary research programs. Environ. Sci. Policy 13 (8) 733-741.

SLAUGHTER S and RHOADES G (1996) The emergence of a competitiveness research and development policy coalition and the commercialization of academic science and technology. Sci. Technol. Human Values 21 303-339.

SNOW CP (1959) The Two Cultures and the Scientific Revolution. Cambridge University Press, Cambridge.

STRYDOM WF, HILL L and ELOFF E (2006) Achievements of the River Health Programme 1994-2004: A National Perspective on The Ecological Health of Selected South African Rivers. Department of Water Affairs and Forestry, Water Research Commission and Council for Scientific and Industrial Research, Pretoria.

VAN VUUREN L (2012) In the Footsteps of Giants: Exploring the History of South Africa's Large Dams. Water Research Commission, Pretoria.

WILLIAMS WD (1989) A Statement on the Inland Water Ecosystems Programme and the Current State of Limnology in South Africa. Foundation for Research Development, CSIR, Pretoria.

WORTHINGTON EB (1983) The Ecological Century: A Personal Appraisal. Clarendon Press, Oxford.

ZIMAN J (1996) Is science losing its objectivity? Nature 382 751-754. 